\title{
Percutaneous dissolution of gallstones using methyl tert-butyl ether
}

\author{
Johnson L Thistle, MD, BRet T Petersen, MD, Claire E Bender, MD,
} ANDREW J LEROY, MD, TIMOTHY M RIDGWAY, MD

\begin{abstract}
Radiolucent cholesterol gallstones can be dissolved rapidly by methyl tert-butyl ether (MTBE) introduced directly into the gallbladder. Percutaneous transhepatic catheter placement is a well established interventional radiology procedure and is the preferred route for MTBE administration. A small number of patients have been treated using nasobiliary placement of a gallbladder catheter. Rapid stirring automatic pump systems allow dissolution of most cholesterol stones, but some may require extracorporeal shock wave lithotripsy to achieve complete dissolution and aspiration of debris. Large bore percutaneous fragmentation and extraction methods require general anesthesia but are applicable to pigment stones. Can J Gastroenterol 1990;4(9):624-627
\end{abstract}

Key Words: Direct contact dissolution, Gallstones, MTBE

\section{La dissolution percutanée des lithiases biliaires par instillation de méthyl tert-butyl éther}

RESUME: Les lithiases cholestéroliques radiotransparentes sont aisément dissoutes par instillation directe de méthyl tert-butyl éther (MTBE) dans la vésicule biliaire. La mise en place d'un cathéter transhépatique percutané est une intervention radiologique bien établie et représente la voie préférée pour l'administration du MTBE. Un petit nombre de patients ont été traités par drainage nasobiliaire. Les pompes rotatives rapides viennent à bout de la plupart des calculs cholestéroliques mais pour parvenir à la dissolution et à l'aspiration complètes des débris, il est parfois nécessaire de recourir à une lithotritie extracorporelle par ondes de choc (LEOC). Une anesthésie générale est nécessaire à la fragmentation et à l'extraction des gros calculs, méthodes qui s'appliquent également aux calculs pigmentaires.

Mayo Medical Center, Rochester, Minnesota, USA

Correspondence and reprints: Dr JL Thistle, Division of Gastroenterology, Mayo Clinic, Rochester, MN 55905, USA
$\mathrm{R}$ ADIOLUCENT CHOLESTEROL GALL. stones can be rapidly dissolved in vitro by methyl tert-butyl ether (MTBE) (1). This rapidly effective cholesterol solvent is an alkyl ether liq. uid at body temperature (boiling point $55^{\circ} \mathrm{C}$ ) and will dissolve even large cholesterol stones (4 to $6 \mathrm{~cm}$ in diameter) within hours (2). Animal and human studies have demonstrated little toxicity when MTBE is retained in the gallbladder $(2,3)$. Continuous in. fusion into the duodenum may produce duodenitis and extensive systemic ab. sorption can induce intravascular hemolysis. Both of these side effects can easily be avoided by retrieval of most of the administered MTBE. This solvent remains investigational for human use in the United States.

\section{PERCUTANEOUS \\ TRANSHEPATIC CATHETER PLACEMENT \\ Introduction of a $5 \mathrm{~F}(1.7 \mathrm{~mm})$ pigtail catheter through the hepatic-gallblad- der attachment into the gallbladder can be performed using either fluoroscopic or ultrasound targeting for initial entry}



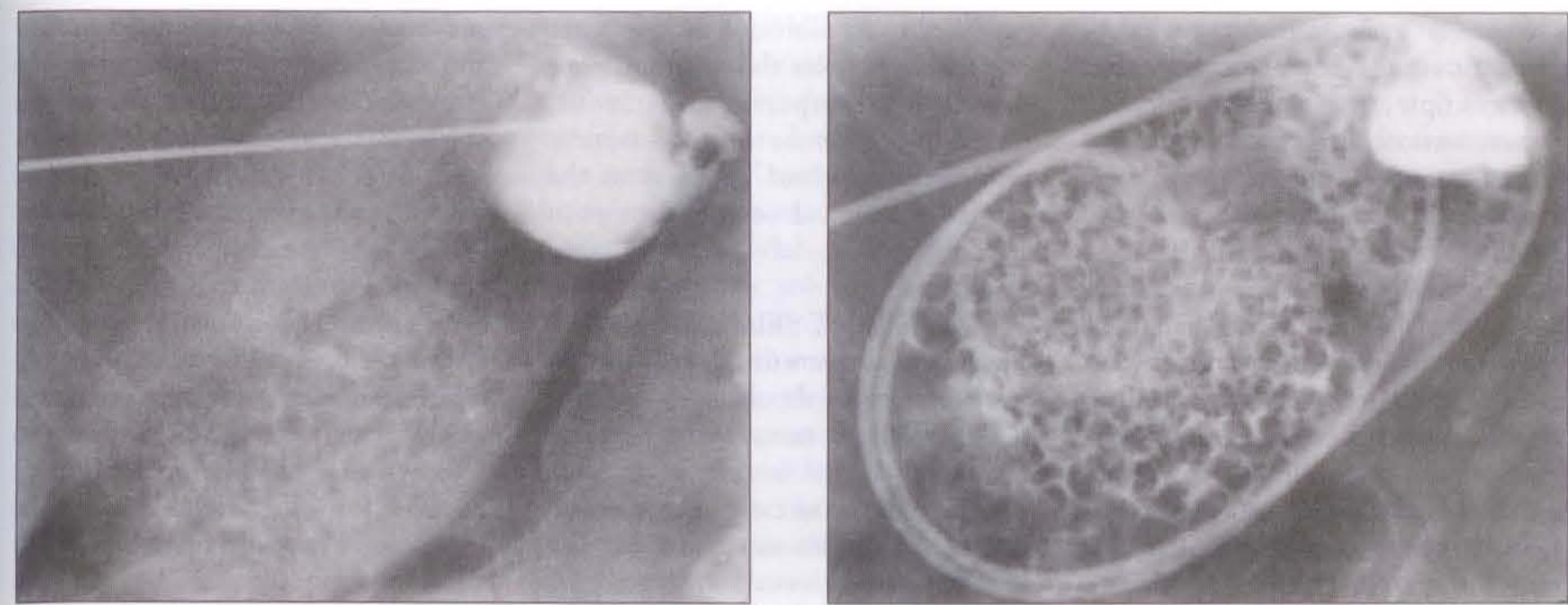

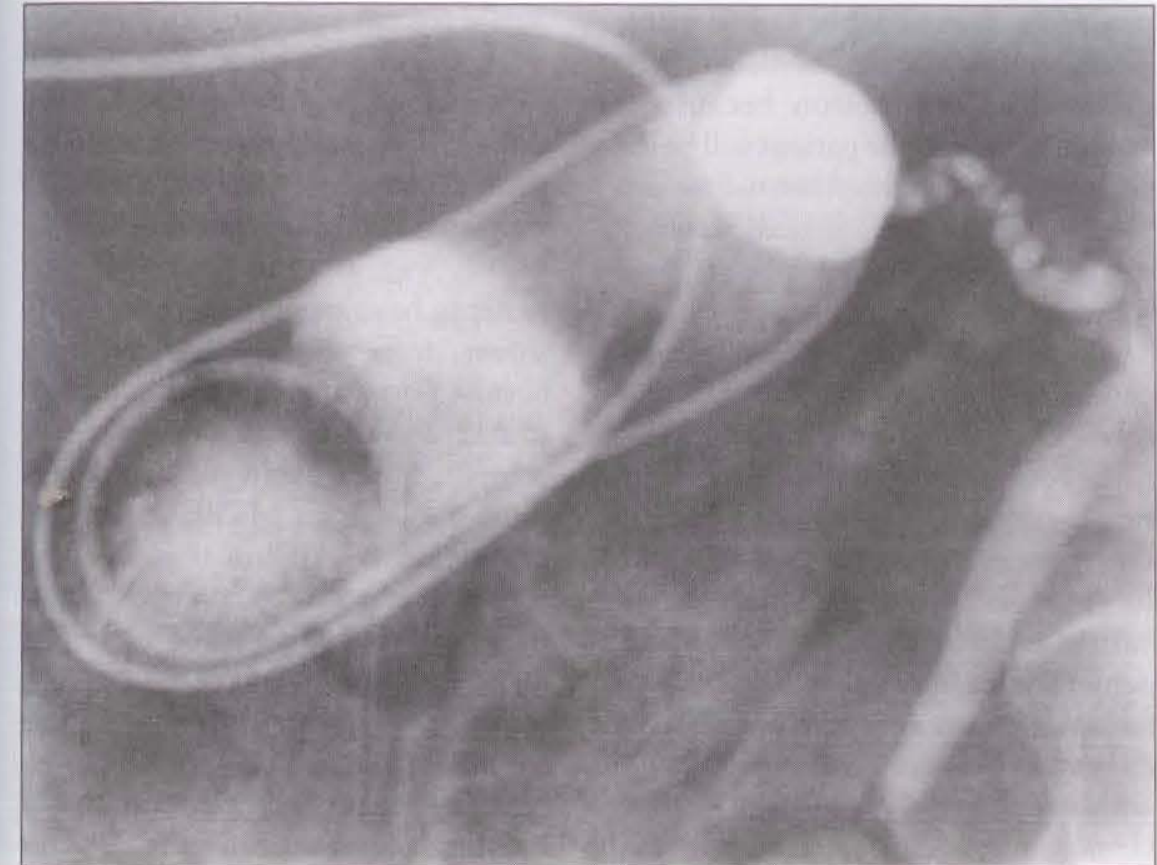

into the gallbladder (Figure 1). Mayo Clinic interventional radiologists have successfully placed catheters in 130 consecutive patients regardless of gallbladder anatomy, extent of hepatic attachment or gallbladder wall thickness. Discomfort has been managed using local anesthesia and intravenous fentanyl and diazepam. Anticholinergic premedication decreases the risk of vasovagal bradycardia and hypotension.

When gallbladder capacity permits, one or two loops of the pigtail catheter (Cook Inc, Bloomington, Indiana) are placed in the gallbladder with the pigtail preferably in the fundus. This min- imizes the potential for migration of the catheter out of the gallbladder. The small diameter catheter and transhepatic tract allow removal of the catheter as soon as stone dissolution is complete, providing there is not extravasation at the gallbladder wall entry site when the gallbladder and ducts are filled with contrast. The potential for bile leakage after catheter removal can be minimized by leaving the catheter in place for several days, and this is prudent if substantial extravasation is apparent or if little or no gallbladder attachment to the liver is present. Gelfoam (UpJohn, Michigan) may be
Figure 1) Top left Percutaneous transhepatic gallbladder puncture using a 22 gauge needle under fluoroscopic guidance. Initial gallbladder opacification for targeting was achieved by oral radiopaque contrast media. Top right Two loops of a $5 \mathrm{~F}$ polyethylene pigtail catheter (Cook Inc, Bloomington, IN) have been placed in the gallbladder assuring a sufficiently stable position of the catheter. Infusion holes are located only in the pigtail segment. Left Complete dissolution of the stones and a patent, stone-free duct system are demonstrated before removal of the catheter. Ultrasonography the following moming revealed no residual stone material

placed in the transhepatic track to decrease the risk of bile leak via this route.

\section{NASOBILIARY CATHETER PLACEMENT}

Endoscopic retrograde catheterization of the cystic duct can be achieved in most patients. The present authors and others have placed nasobiliary catheters into the gallbladder for gallstone dissolution in a small number of patients but experience, especially in patients without dilated cystic ducts, is insufficient to predict an incidence of success $(4,5)$. Stone dissolution by nasobiliary catheter presents potential 
advantages and disadvantages compared with the percutaneous approach. For example, patient tolerance of catheterization of the cystic duct, and ease of creation of stirring in the gallbladder and of aspiration of insoluble debris through a long small diameter catheter need to be determined. Anatomic anomalies in the gallbladder will be more difficult to deal with at long distance.

Some patients prefer percutaneous placement to swallowing an endoscope and having a nasobiliary catheter in place. Nevertheless, endoscopic retrograde catheter placement deserves careful evaluation and perhaps randomized comparison with the well tolerated, safe and effective percutaneous method.

\section{GALLSTONE DISSOLUTION}

Once the gallbladder catheter is in position, as many stones as possible are corralled within the circumference of the pigtail where stirring and consequently dissolution is most effective. The volume of radiopaque contrast material which envelopes the stones but does not extravasate at the catheter entry sitelor overflow into the cystic duct is determined. The volume of MTBE to be continuously infused and aspirated is that volume which will surround the stones but is several millilitres less than overflow volume. As long as this volume is greater than the dead space in the catheter, rapid dissolution can be achieved, often using only 2 or $3 \mathrm{~mL}$ of MTBE. Indeed, a small volume rapidly infused and aspirated induces more rapid dissolution than a large volume. Initial experience has been with a manual syringe technique during which the gallbladder is completely evacuated of all MTBE, bile and stone debris with each aspiration four to six times a minute. To avoid saturation with cholesterol, the treatment volume is equilibrated with 10 to $15 \mathrm{~mL}$ of MTBE in the syringe with each aspiration, and this reservoir volume is exchanged for fresh MTBE every 5 to 15 mins. The authors have recently initiated testing of an automatic pump system developed jointly with Baxter Healthcare (Irvine, California) $(6,7)$. This compressed air driven system produces rapid stirring which in vitro more than doubles the speed of stone dissolution compared to a manual method. Multicentre trials of this pump system are expected to begin in the United States and other countries in 1990.

\section{PATIENT SELECTION}

Only patients with specific biliary stone symptoms should be considered for therapeutic intervention, except under unusual circumstances. If cystic or common bile duct stones are present, treatment may be successful, but dissolution or extraction of duct stones adds to the difficulty and length of the procedure. Success is not as predictable as with stones in the gallbladder only. If cystic duct obstruction because of fibrosis is present, the patient will be left with hydrops and the potential for empyema in the future. Methods for ablating the gallbladder have not yet been shown to be safe and effective (8).

Cholesterol stones radiolucent on computed tomography scan will dissolve within one to three days leaving no or very minimal residual debris with rare exceptions (2). Based on in vitro data, many stones which are radiolucent by abdominal plain film but containing diffuse or rim calcium demonstrable by computed tomography scan may be dissolved with MTBE using the automatic pump system (9). Stones with more extensive calcification may be more efficiently treated nonsurgically by predissolution fragmentation using extracorporeal shock wave lithotripsy (10). If stones are radiolucent on computed tomography scan, however, solitary stones as large as $4 \mathrm{~cm}$ can be completely dissolved within 2 or $3 \mathrm{~h}$ without fragmentation. Indeed, fragmentation might scatter debris throughout the gallbladder or even the cystic duct, whereas a solitary stone will remain within the pigtail zone until completely dissolved.

The presence of irreversible coagulopathy, hepatic abscess or hemangioma in the potential transhepatic catheter path are contraindications to this procedure. Patients with acute cholecystitis who have a substantially increased risk for surgery can have catheter cholecystostomy performed and then dissolution therapy after resolution of the acute inflammation. The most ideal candidates for MTBE treatment are patients with increased risk for surgery and with cholesterol stones having little or no calcium apparent on computed tomography scan. A variety of other patients may also be candidates for this treatment if nonsurgical therapy is preferred. Cholesterol stones retained in the duct system can be dissolved rapidly with MTBE but additional methods for retention and retrieval of MTBE must be incorporated.

\section{RESULTS}

Treatment with MTBE has been well tolerated in 130 consecutive patients including two with duct stones, three with cholecystostomies, and eight treated with sequential extracorporeal shock wave lithotripsy followed by MTBE fragment dissolution. In four patients, having one, two, three and 14 stones, respectively, all less than or equal to $5 \mathrm{~mm}$ in diameter, although stone calcification was not apparent by computed tomography scan, the stones were insoluble in MTBE. All of the other patients with little or no calcification apparent on computed tomography scan have had either no residue debris or small amounts of residue $5 \mathrm{~mm}$ or less in diameter. Only five patients have had debris apparent fluoroscopically but most of the others have had one or more tiny echogenic densities with or without acoustic shadowing detectable by ultrasonogram. This slight residue has not caused duct obstruction, pancreatitis or cholecystitis. Solitary stones up to $6 \mathrm{~cm}$ in maximum diameter have usually been completely dissolved within one or two days, but multiple large mixed cholesterol-pigment stones usually require two to four days of treatment using the manual method. The $5 \mathrm{~F}$ catheter is very well tolerated in almost all patients and is connected to sterile bile bag drainage overnight.

\section{SIDE EFFECTS}

Both catheter placement and MTBE treatment have been well tolerated. When pain has occurred from extra- 
vasation of bile or MTBE, it has been treated with bupivacaine (Marcaine) infusion along the catheter entry tract and intravenous butorphanol (Stadol). By using small volumes of MTBE, the authors have never had to discontinue the procedure because of discomfort, and after the first morning of treatment, most patients do not require further analgesia. Nausea and emesis have been infrequent and transient, and have responded well to prochlorperazine. Although MTBE is liquid at body temperature, it is moderately volatile and flammable and must be handled accordingly. Reasonable precautions to avoid spillage of substantial volumes and proper disposal procedures will minimize any hazard.

\section{REFERENCES}

1. Nelson PE, Moyer TP, Thistle JL. Gallstone dissolution in vitro using methyl tert-butyl ether: Radiologic selection criteria. Gastroenterology 1990;98:1280-3.

2. Thistle JL, May GR, Bender CE, et al. Dissolution of cholesterol gallbladder stones using methyl tert-butyl ether administered by percutaneous transhepatic catheter. N Engl ] Med 1989:320:633-9.

3. Allen MJ, Borody TJ, Bugliosi TF, May GR, LaRusso NF, Thistle JL. Cholelitholysis using methyl tertiary butyl ether. Gastroenterology 1985;88:122-5.

4. Ponchon T, Baroud J, Mestas JL, Chayvialle JA. Gallbladder lithotripsy:

\section{OVERVIEW}

As experience and technology evolve, most patients' stones should be completely dissolved within one or two days with MTBE with minimal morbidity and almost immediate return to work. This methodology should be applicable to other solvents for cholesterol and noncholesterol stone components which may also be found to be safe and effective. Rapid dissolution of stone fragments using MTBE after extracorporeal lithotripsy would avoid complications from fragment passage and provide much more rapid and complete stone clearance than oral bile acid dissolution therapy.

The cost of materials and equipment for MTBE treatment is low, but the

Dissolution of fragments. Gastrointest Endosc 1988;34:468-9.

5. Domschke W. Extracorporeal biliary lithotripsy and direct chemolitholysis An integrated concept. Gastroenterol Jpn 1989;24:597-604.

6. McCullough JE, Lesma A, Thistle JL. A rapid stirring automatic pump system for dissolving gallstones using methyl tert-butyl ether (MTBE): In vitro comparison with the manual syringe method. Gastroenterology 1989;96:A629. (Abst)

7. Ridgway TM, Lesma A, Thistle JL. An automatic pump system for rapid dissolution of gallstones using methyl tertbutyl ether (MTBE): Effect on gallbladder mucosa in swine. procedure usually requires at least $2 \mathrm{~h}$ from both an interventional radiologist and gastroenterologist as well as about $6 \mathrm{~h}$ a day of a paramedical assistant's time. The automatic pump system, however, should shorten dissolution time and allow two or three patients to be supervised by one paramedical assistant. As this and other nonsurgical or minor surgical alternatives to standard cholecystectomy evolve, their cost and ultimate outcome must be assessed and compared. The development of effective, safe and economical methods for prevention of stone recurrence will considerably expand the population of patients for whom nonsurgical treatments will be the therapy of choice.

Hepatology 1989;10:603. (Abst)

8. Becker CD, Quenville NF, Burhenne HJ. Gallbladder ablation through radiologic intervention: An experimental alternative to cholecystectomy. Radiology 1989;171:235-40.

9. Ridgway TM, Stadheim LM, Gray JE, Thistle JL. Complete dissolution of cholesterol gallstones radiopaque on CT scan by methyl tertbutyl ether (MTBE) using an automatic pump system (APS) in vitro. Gastroenterology 1990;98:A259. (Abst)

10. Peine CJ, Petersen BT, Williams HJ, et al. Extracorporeal shock wave lithotripsy and methyl tert-butyl ether for partially calcified gallstones. Gastroenterology 1989;97:1229-35. 


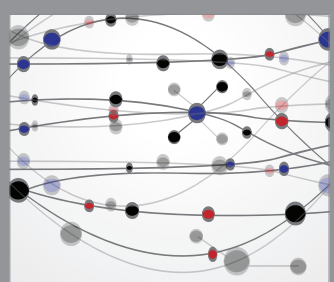

The Scientific World Journal
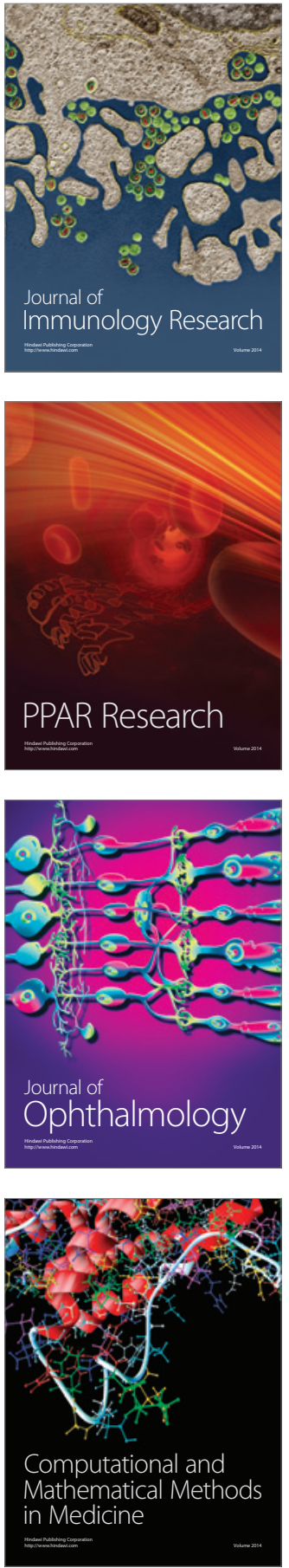

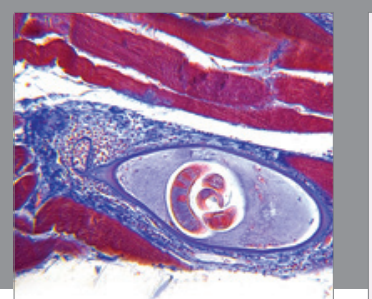

Gastroenterology Research and Practice

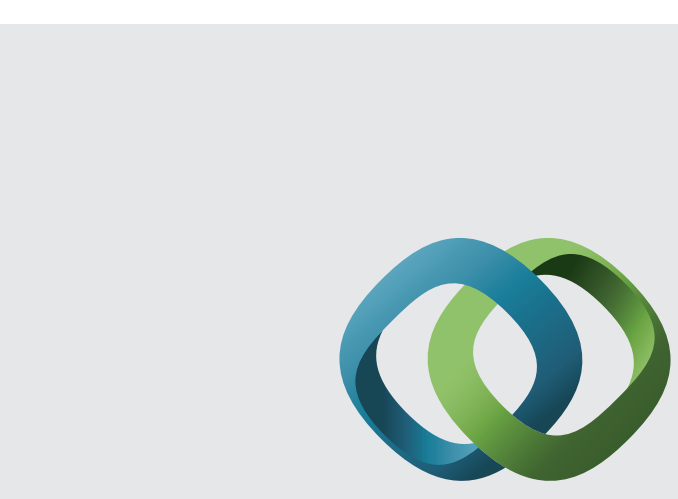

\section{Hindawi}

Submit your manuscripts at

http://www.hindawi.com
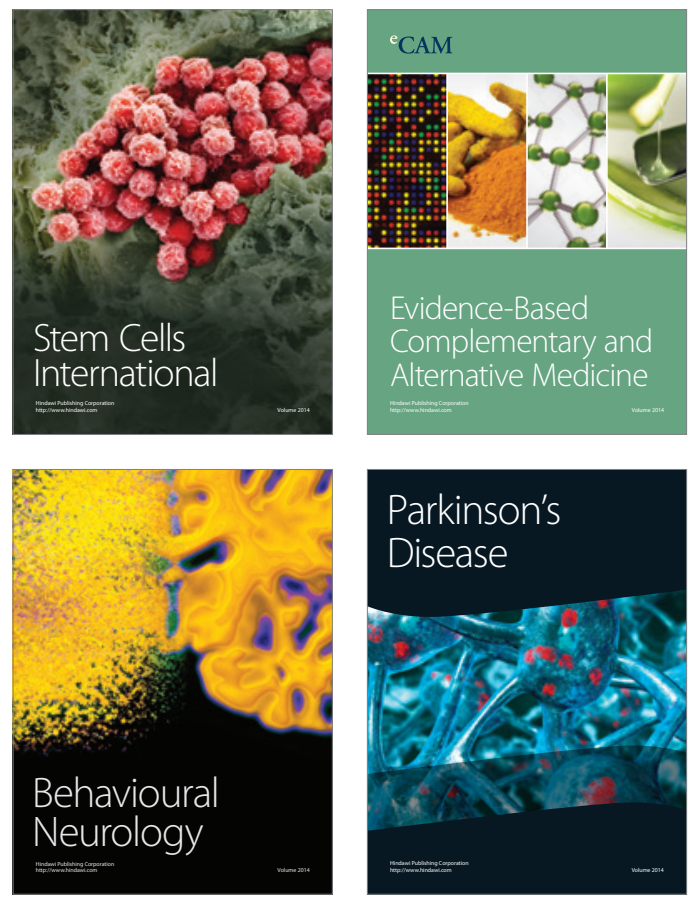
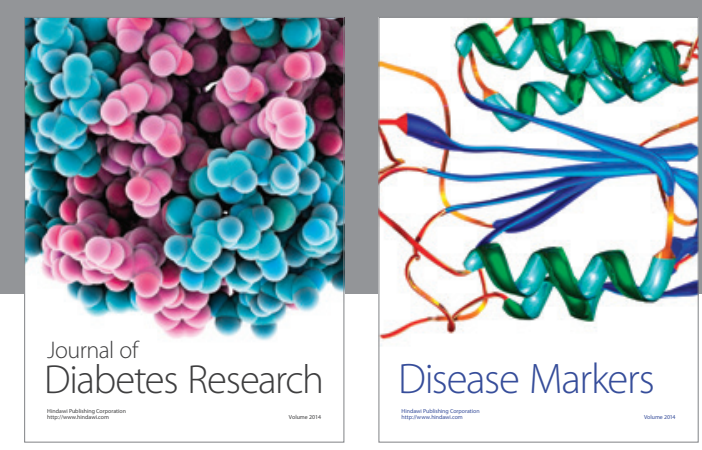

Disease Markers
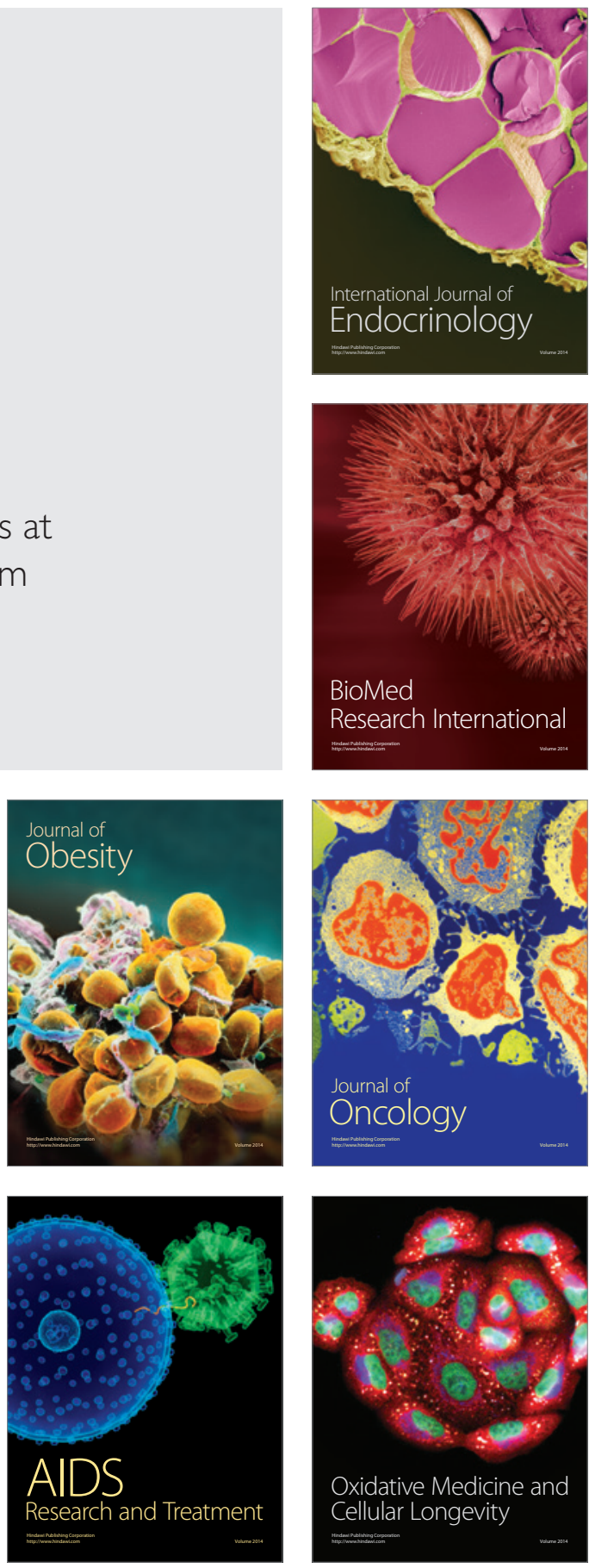